\title{
An Unusual Case of Extensive Intra-Thoracic and Intra-Abdominal Calcifications
}

\author{
Attila Frigy* and Ildikó Kocsis
}

Department of Internal Medicine IV, University of Medicine and Pharmacy of Tîrgu Mureș, Tîrgu Mureș, Romania

${ }^{*}$ Corresponding author: Attila Frigy, Director, Department of Internal Medicine IV, University of Medicine and Pharmacy of Tîrgu Mureș, Tîrgu Mureș, Romania, Tel: +40 265215 551; E-mail: afrigy68@gmail.com

Rec Date: August 12, 2017, Acc Date: September 10, 2017, Pub Date: September 12, 2017

Citation: Frigy A, Kocsis I (2017) An Unusual Case of Extensive Intra-Thoracic and Intra-Abdominal Calcifications. Med Case Rep Vol.3 No.4:50.

\section{Abstract}

The paper presents a rare case of massive visceral calcifications in a patient with congestive heart failure caused by effusive-constrictive pericarditis. The thoracic and abdominal CT demonstrated extensive visceral calcifications, including huge, shell-like perirenal calcified masses. Highly elevated parathormone levels revealed the diagnosis of a long lasting hyperparathyroidism as substrate for our findings.

Keywords: Hyperparathyroidism; Calcifications; Constrictive pericarditis

\section{Introduction}

In the daily practice the clinician frequently meet common cases, like those with heart failure, having the risk to fall in the routine approach of management, but sometimes - like in our case-a good spirit of observation, combined with modern imaging techniques could reveal rare and impressive substrates of the clinical situation.

\section{Case Presentation}

A 73-year-old man was referred to our clinic with the diagnosis of congestive heart failure, the main reason for admission being generalized edema, right pleural effusion and ascites. Transthoracic echocardiography revealed the presence of an effusive-constrictive pericarditis as substrate of heart failure. The typical pattern of cardiac remodeling, evidence of interdependence of ventricular filling and the presence of a thickened pericardium with effusion (with a maximum diameter of $9 \mathrm{~mm}$ ), containing fibrin deposits, was diagnostic in this regard (Panel A). On the physical examination, superficial masses with bony consistency were palpable in the upper part of the abdomen. Computer tomography revealed unusually massive intra-thoracic (including pericardial) and intra-abdominal, superficial, and deep, intra- and retroperitoneal, calcified masses (Panel $B$ and $C$ with arrows). The most spectacular were the "shells" accompanying the two kidneys (Panel D with arrows). Also, left hydronephrosis was present due to nephrolithiasis (Figure 1).

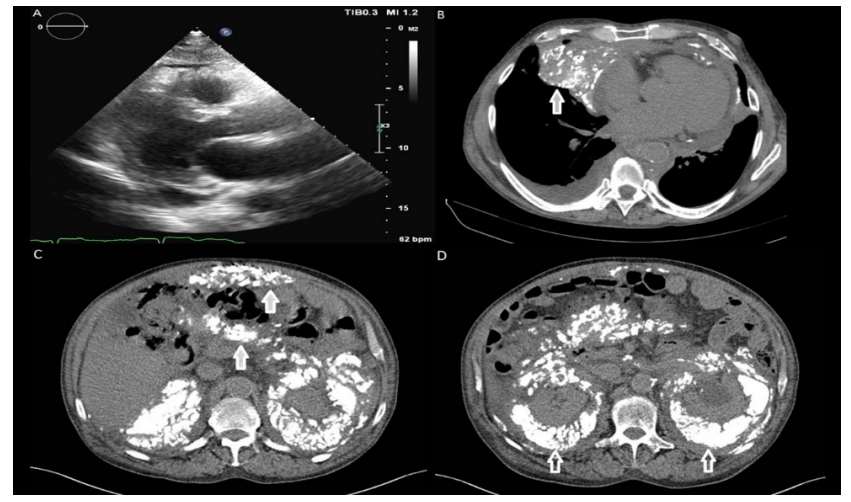

Figure 1 Extensive intra-thoracic and intra-abdominal calcifications.

Panel A - Pericardial thickening and effusion on echocardiography (parasternal long axis view).

Panel B - Intra-thoracic (arrow) and pericardial calcifications.

Panel C - Superficial and profound (arrows) intraperitoneal calcifications.

Panel D - Massive retroperitoneal calcifications with shelllike appearance accompanying the two kidneys (arrows).

\section{Discussion}

Our patient, admitted with congestive heart failure, was found with extensive intra-thoracic and intra-abdominal calcifications. The possible causes include malignant and benign conditions, the most frequent being: after (recurrent) peritonitis, calcifying fibrous tumor, encapsulating peritoneal sclerosis, metastatic ossifications, hyperparathyroidism, metastatic calcified adenocarcinoma, soft tissue sarcomas $[1,2]$. The generalized character of calcifications leads us to the possible diagnosis of long-lasting primary hyperparathyroidism (PHPT) which was confirmed by the highly elevated serum parathormone level (142 pg/ml).

\section{Conclusion}

In this case, we found a normocalcemic variant (total Ca 9.1 $\mathrm{mg} / \mathrm{dl}$, ionic Ca $4.01 \mathrm{mg} / \mathrm{dl}$ ), which was interpreted in the context of low level of 1,25 dihydroxyvitamine $D(18.4 \mathrm{pg} / \mathrm{ml})$. 
This form of PHPT is nor a mild or benign condition, and the patients could present the same clinical features as those with hypercalcemia $[3,4]$.

\section{References}

1. Agarwal A, Yeh BM, Breiman RS, Qayyum A, Coakley FV (2004) Peritoneal calcification: Causes and distinguishing features on CT. Am J Roentgenol 182: 441-445.
2. Frank SJ, Friedman S, Flusberg M, Wolf EL, Stein MW (2014) Outside the inside: A review of soft-tissue abnormalities seen on thoracoabdominal computed tomography. Can Assoc Radiol J 65: 327-334.

3. Bandeira L, Bilezikian J (2016) Primary hyperparathyroidism. Ulus Cerrahi Derg 32: 58-66.

4. Saliba W, Lavi I, Rennert HS, Rennert G (2012) Vitamin D status in primary hyperparathyroidism. Eur J Intern Med 23: 88-92. 